Article Review

\title{
Keanekaragaman Bulu Babi (Echinoidea) di Perairan Kepulauan Seribu Indonesia
}

\section{Sukardi Rahman*}

*Jurusan Manajemen Sumber Daya Perairan, Fakultas Perikanan dan IImu Kelautan Universitas Negeri Gorontalo. Email: ardyrahman39@gmail.com

\section{Introduction}

Negara yang memiliki kekayaan akan alam flora dan fauna adalah salah satunya Indonesia, misalnya dalam ekosistem lautnya terdapat berbagai macam kekayaan yang dijadikan sumber kehidupan manusia (Bengen,2000 dalam Yudasmara,2013) Salah satunya adalah Bulu Babi, di Dunia terdapat sekitar 6000 jenis Echinodermata yang sekitar 950 adalah Bulu babi, 84 jenis Bulu babi yang masing masing diantaranya 48 Genera dan 31 dari golongan Famili terdapat dan dimiliki di indonesia (Clark dan Rowe,1971 dalam Firmandana, 2014), Echinodermata merupakan hewan yang umumnya merupakan hewan yang memiliki ciri dapat dilihat dari luar dengan adanya kulit yang berduri yang dimilikinya dan terbagi atas 5 kelas yaitu Kelas Echinoidea,Crinoida, Esteroidea,Ophiuroidea, dan yang terakhir adalah Holothuroidea(Jasin,1984 dalam Satyawan,2014). Umumnya Bulu Babi atau Echinoidea dapat ditemukan disekitaran Terumbu karang dan terdapat di perairan dangkal dan penyebarannya bisa sampai meluas di daerah sekitaran perairan dan penyebaranya dapat di pengaruhi dari Berbagai Faktor lingkungan misalnya faktor Fisika Maupun faktor Kimia (Sugiarto, 1995 dalam Arhas, 2018; Nane dkk., 2020), Menurut pendapat (Wardhana, 1990 dalam Noviana 2019) Bahwa Bulu Babi merupakan salah satu hewan yang memakan jenis-jenis alga dikarenakan hewan in tergolong dalam hewan herbivora yang artinya hewan pemakan jeni-jenis tumbuhan yang sering kali menempel pada terumbu karang.

Zona penyebaran Bulu babi sangatlah meluas hampir disemua kawasan lautan dan dapat bertahan hidup sesuai adaptasinya masing-masing yang saling berinteraksi dan memiliki banyak keanekaragaman (Toha, 2019) Bulu Babi merupakan pengendali dari berbagai macam Makroalgae yang dapat merusak terumbu karang sehingganya Bulu Babi memiliki peran penting akan kelangsungan Bulu Babi, sehingganya apabila Bulu babi disuatu daerah Itu berkurang maka di Pastikan daerah perairan tersebut terumbu karangnya ikut mengalami penurunanan populasi sehingganya populasi Bulu Babi Harus berjalan hidup seimbang agar tetap terjaganya Ekosistem Perairan (Nystrom et al,2000 dalam Miala, 2015) Menurut banyaknya suatu spesies Bulu Babi ini 
tergantung pada faktor dari abiotik dan Biotik(Yunita, 2020). sehingganya kita dapat mengetahui bahwa Bulu Babi merupakan suatu Spesies yang menjadi Gembok dari kelangsungan hidup terumbu Karang (Purwandatama,2013). Selain terumbu karang terdapat juga Ekosistem Lamun yang merupakan tempat mencari makan hewan inverte brata, sehingga apabila suatu ekosistem lamun itu hidup subur dan lebat maka akan membuat kelimpahan, keragaman, dan suatu populasi invertebrata itu menjadi lebih meningkat dan bulu Babi mencari makan itu hidup secara berkelompok untuk saling melindungi dari ancaman ( Rumahlatu,2012).

Selanjutnya Echinodermata dapat kita jumpai di sekitaran perairan yang memiliki kualitas air yang cukup bersih ataupun jernih, karena kebanyakan spesies ini menetralisir kandungan nutrien yang menyebabkan terjadinya air keruh sehingga apabila terdapat echinodermata disuatu perairan itu maka air yang menjadi tempat hidupnya sudah bisa dipastikan itu jernih dan dalam kondisi yang tenang (Radjab et al 2014 dalam Sese,2018) selain itu kita dapat menjumpai dalam padang lamun kelompok yang tergolong dalam Echinodermata Salah Satunya Bulu Babi (Echinoidea yang merupakan kelas yang yang menempati daerah tersebut(Aswandy dan Azkab,2000 dalam Laning dkk,2014), Menurut (Barkeland,1989 dalam Yusron, 2010) Bahwa kelompok Echinodermata memanfaatkan terumbu karang sebagai tempat mencari makan dan tinggal untuk menjauhi diri dari predator, dan Echinodermata sendiri sangat dibutuhkan dan memiliki hubungan dengan mahkluk lain terutama di bagian rantai makanan, karena kebanyakan bulu babi sering kali memakan jenis detritus dan predator yang dapat menganggu.

Ciri khusus yang kita dapat temukan di Bulu Babi yaitu terdapat cangkang yang memiliki pigmen yang melapisi dan berwarna hitam, memiliki cangkang yang kuat, dan dibagian seluruh tubuhnya terdapat duri-duri yang melindungi tubuhnya yang bahkan terdapat racun disatu jenis Bulu Babi tertentu (Afifa,2018) Kebanyakan Bulu Babi itu hanya aktif pada malam hari karena Bulu babi pada umumnya menempati sekitaran terumbu karang, seperti yang kita ketahui bahwa terumbu karang merupakan Ekosistem yang subur sehingga dapat kita ketahui bahwa di terumbu karang pasti hidup mahkluk hidup lain selain Bulu babi, sehingga Bulu babi hanya keluar pada malam har i untuk menghindari dari dari predator (Firmandana, 2014 dalam Arthaz 2015 ). Kelas Echinoidea termasuk dalam kelas yang memiliki manfaat atau peran penting dalam kehidupan salah satunya dapat dijadikan sebagai bioindikator atau sebagai organisme yang digunakan untuk melakukan pemantauan perairan seperti laut, karena Bulu Babi Memiliki Respon yang tinggi tau memiliki daya sensitifitas terhadap perubahan-perubahan yang terjadi di lingkugannya (Rumahlatu,2012 ), Selain itu menurut (Toha,2007 dalam Silaban 2014), bahwa bahwa kebanyakan para ilmuwan 
menggunakan Bulu babi yang paling banyak digunakan adalah untuk mengenal apa itu Regulasi, Toksikologi, biologi reproduksi,gen evolusi biologi dan embriologi, selain hal itu pula bulu babi memiliki nilai jual yang tinggi karena mulai dari durinya dapat dijadikan sebagai hiasan, dapat dibuatkan menjadi pupuk penyubur, dan dalam dunia medis sering digunakan menjadi obat obatan.

Menurut (Afifudin dkk, 2014) Juga bahwa di indonesia banyak jenis dari Bulu Babi belum di manfaatkan secara besar besaran oleh masyarakat, hanya saja hanya sebagian masyarakat yang menggunakan Bulu Babi sebagai bahan pakan ternak tambahan, dan biasa hanya dijadikan makanan peganti dari ikan, untuk di makan dengan nasi, selain itu Bulu babi memiliki sering kali diekspor sampai keluar negeri karena nilainya ekonominya yang cukup relatif mahal, terutama di bagian Gonadnya (Nane, 2019a). Ada beberapa macam jenis Echinoidea yang ditemukan dan mendominasi di salah satu diperairan Kepulauan Seribu yaitu antara lain Diadema setosum, Mespilia globulus, Laganum laganum, Diadema setosum adalah yang tergolong dalam keluarga Diadematiae, jenis spesies ini dapat kita temukan 2 sisi yaitu oral dan Aboral dibagian mulutnya terletak di sisi Oral sendangkan anal ring yang berwarna jingga terdapat di Aboral dan spesies ini memiliki aboral yang berwarna hitam setiap bagian tubuhnya (Triana dkk, 2015) banyaknya densitas Bulu babi jenis Diadema Setosum di pengaruhi oleh terumbu karang berbanding terbalik dengan pernyataan yang sesuai yaitu bahwa apabila kondisi terumbu karang rendah maka kepadatan dari Bulu Babi jenis ini akan tinggi, dan sebaliknya apabila tingkat kondisi terumbu karang tinggi maka kepadatan Bulu babi jenis ini akan menurun (Setiawan,2012), Ada faktor luar lain juga yang mempengaruhi kurangnya jumlah Bulu Babi yaitu berasal dari akibat adanya pencemaran limbah ke perairan, misalnya adanya buangan air limbah deterjen di laut (Supono dan Arbi, 2012) dan kegiatan penangkapan (Nane, 2019b).

Selain itu Menurut Pendapat (Lubis, 2017) bahwa bulu babi jenis D. Setosum memiliki ciri-ciri yang dapat dibedakan dengan jeni Bulu babi yang lain antara lain hidup di daerah yang memiliki substrat berpasir, bentuk tubuhnya pipih, memiliki warna orange, hitam dan sedikit agak kebiruan memiliki duri yang sangat panjang berfungsi untuk menghindarkan dan menakuti predator yang akan memangsanya. Selain itu ada jenis bulu babi yang sangat berbahaya durinya yaitu bulu babi jenis Echinometra mathaei(Syam dkk, 2017). Jenis Bulu Babi yang kedua ditemukan adalah mespilia globulus, kebanyakan dititik perairan jenis bulu babi ini agak rendah karena spesies ini kebanyakan tidak hidup berkelompok melainkan hidup menyendiri (Vindia dkk, 2019) jenis Bulu Babi mespilia globulus ini paling banyak di konsumsi masyarakat di Pulau Tomia (Nane, 2019c; 2019d). Dan menurut (Huda, 2016) mespilia Globulus merupakan hewan yang tergolong dalam Ordo 
Phymosomatoida yang memiliki ciri yaitu turbekel nya tidak berlubang dan memiliki plate yang menyatu di lentera Aristotelesnya. Selanjutnya yang terakhir ditemukan di sekitar perairan kepulauan seribu adalah jenis Bulu Babi Laganum laganum yang merupakan spesies ketiga yang ditemukan, spesies ini termasuk dalam jenis Bulu babi, atau yang sering disebut dengan dolar pasir(Nurafni,2019) jenis-jenis laganum sp antara lain Laganum retinens, Laganum boschi,Laganum dickersoni,Laganum decagonale, Laganum deppressum, laganumCentrale(Suryanti, 2018) menurut Afian dkk, 2013) Bahwa Spesies ini termasuk dalam kelas Echinoidea yang memiliki bentuk tubuh yang Bilateral,bulat, dan pipih atau yang sering disebut dengan Iregular. Dan spesies ini hidup di dasar perairan yang memiliki substrat berlumpur dan berpasir(Masruroh,2014).

\section{Conclusion}

Berdasarkan penjelasan diatas bahwa indonesia merupakan satu kawasan yang memiliki akan kekayaan flora dan fauna, terutama fauna yang berasal dari filum Echinodermata kelas Echinoidea atau salah satu spesiesnya Bulu babi, yang biasa menempati daerah kawasan Ekosistem Terumbu Karang dan Ekosistem Lamun. Ciri khusus yang kita dapat temukan di Bulu Babi yaitu terdapat cangkang yang memiliki pigmen yang melapisi dan berwarna hitam, memiliki cangkang yang kuat, dan dibagian seluruh tubuhnya terdapat duri-duri yang melindungi tubuhnya yang bahkan terdapat racun disatu jenis Bulu Babi tertentu, Ada beberapa macam jenis Echinoidea yang ditemukan dan mendominasi di salah satu diperairan Kepulauan Seribu yaitu antara lain Diadema setosum, Mespilia globulus, Laganum laganum. mespilia Globulus merupakan hewan yang tergolong dalam Ordo Phymosomatoida yang memiliki ciri yaitu turbekel nya tidak berlubang dan memiliki plate yang menyatu di lentera Aristotelesnya, sendangkan Diatema setosum adalah yang tergolong dalam keluarga Diadematiae, dan spesies ini termasuk dalam jenis Bulu babi, atau yang sering disebut dengan dolar pasir.

\section{References}

Afifa, F. H., Supriharyono, S., \& Purnomo, P. W. (2018). Penyebaran Bulu Babi (Sea Urchins) Di Perairan Pulau Menjangan Kecil, Kepulauan Karimunjawa, Jepara. Management of Aquatic Resources Journal, 6(3), 230-238 
Arhas, F. R., Mahdi, N., \& Kamal, S. (2018). Struktur Komunitas Dan Karakteristik Bulu Babi (Echinoidea) Di Zona Sublitoral Perairan Iboh Kecamatan Sukakarya Kota Sabang.Prosiding Biotik, 2(1).

Arthaz, C. P. (2015). Hubungan Kelimpahan Bulu Babi (Sea Urchin) Dengan Bahan Organik Substrat Dasar Perairan Di Pantai Krakal, Yogyakarta. Management of Aquatic Resources Journal, 4(3), 148-155.

Afian, A. N., \& Purwanti, F. (2013). Pengaruh Kedalaman dan Jarak dari Pantai terhadap Kelimpahan dan Pola Sebaran SandDollar di Pantai Barakuda Pulau Kemujan Taman Nasional Karimunjawa. Management of Aquatic Resources Journal, 2(4), 127-135.

Afifudin, I. K., Suseno, S. H., \&Jacoeb, A. M. (2014). Profil asam lemak dan asam amino gonad bulu babi. Jurnal Pengolahan Hasil Perikanan Indonesia, 17(1), 60-70.

Silaban, B., \&Srimariana, E. S. (2014). Kandungan Nutrisi Dan Pemanfaatan Gonad Bulu Babi (Echinothrixscalamaris) Dalam Pembuatan Kue Bluder. Jurnal Pengolahan Hasil Perikanan Indonesia, 16(2).

Firmandana, T. C. (2014). Kelimpahan Bulu Babi (Sea Urchin) pada Ekosistem Karang dan Lamun di Perairan Pantai Sundak, Yogyakarta. Management of Aquatic Resources Journal, 3(4), 4150.

Huda, M. A. I. (2016). Keanekaragaman Jenis Echinoidea Di Zona Intertidal Pantai Jeding Taman Nasional Baluran.

Laning, T. H., Yusup, D. S., \&Wiryatno, J. (2014). Sebaran Bulu Babi (Echinoidea) Di Kawasan Padang Lamun Pantai Merta Segara, Sanur-Bali. Jurnal Biologi Udayana, 18(2).

Lubis, S. A., Purnama, A. A., \& Yolanda, R. (2017). Spesies Bulu Babi (Echinoidea) Di Perairan Pulau Panjang Kabupaten Bangka Tengah Provinsi Bangka Belitung. Jurnal Ilmiah Mahasiswa FKIP Prodi Biologi, 3(1).

Masruroh, N. H., \& Purwanti, F. (2014). Kelimpahan Dan Pola Persebaran SandDollar Berdasarkan Lokasi Kegiatan Yang Berbeda Di Perairan Pulau Pramuka Kepulauan Seribu. Management of Aquatic Resources Journal, 3(4), 175-180.

Miala, I., Pratomo, A., \& Irawan, H. (2015). Hubungan Antara Bulu Babi, Makroalgae Dan Karang Di Perairan Daerah Pulau Pucung. Repository UMRAH.

Motriana, R., Elfidasari, D., \& Vimono, I. B. (2015, June). Indentificationofechinoderms In Southern Pulau Tikus, Gugusan Pulau Pari, Kepulauan Seribu, Jakarta. Prosiding Seminar Nasional Masyarakat Biodiversitas Indonesia 1(3), 455-459 
Nane, L. (2019a). Efisiensi Mesin Teknologi Sapurata Dalam Mengoptimalisasi Produksi Inovasi Pangan Kukure Di Pulau Barrang Lompo, Makassar. https://doi.org/10.31230/osf.io/q8spg

Nane, L. (2019b). Impact of overfishing on density and test-diameter size of the sea urchin Tripneustes gratilla at Wakatobi Archipelago, south-eastern Sulawesi, Indonesia. BioRxiv, 727271. https://www.biorxiv.org/content/10.1101/727271v1

Nane, L. (2019c). Sea Urchin Sustainability Studies Based on Dimension Biology, Ecology and Technology at Around of Tolandono Island and Sawa Island at Wakatobi Conservation Area. https://doi.org/10.31230/osf.io/4whz6

Nane, L. (2019d). Studi Keberlanjutan Perikanan Landak Laut Berdasarkan Dimensi Biologi, Ekologi Dan Teknologi Di Sekitar Pulau Tolandono Dan Pulausawa Kawasan Konservasiwakatobi [Skripsi, Universitas Hasanuddin]. Https://Marxiv.Org/9zdvr/

Nane, L., Baruadi, A. S. R., \& Mardin, H. (2020). The density of the blue-black urchin Echinotrix diadema (Linnaeus, 1758) in TominiBay, Indonesia. Tomini Journal of Aquatic Science, 1(1), 16-21. https://doi.org/10.37905/tjas.v1i1.5939

Nurafni, N., Muhammad, S. H., \&Sibua, I. (2019). Keanekaragaman Echinodermata di Perairan Pulau NgeleNgele Kecil, Kabupaten Pulau Morotai. Jurnal Ilmu Kelautan Kepulauan, 2(2).

Noviana, N. P. E., Julyantoro, P. G. S., \& Pebriani, D. A. A. (2019). Distribusi dan Kelimpahan Bulu Babi (Echinoidea) Di Perairan Pulau Pasir Putih, Desa Sumberkima, Buleleng, Bali. Current Trends in Aquatic Science, 2(1), 22-29.

Pratama, F. R., Suryanti, S., \& Suryanto, A. (2018). Pemetaan Sebaran Echinodermata Pada Karakteristik Perairan Pulau Menjangan Kecil, Taman Nasional Karimunjawa (Mapping The Echinodermsdistribution In Coastalcharacteristicsof Menjangan Kecil Island, Karimunjawa National Park). Management of Aquatic Resources Journal, 6(4), 415-422.

Purwandatama, R. W., \& Ain, C. (2013). Kelimpahan Bulu Babi (Sea Urchin) pada Karang Massive dan Branching di Daerah Rataan dan Tubir di LegonBoyo, Pulau Karimunjawa, Taman Nasional Karimunjawa. ManagementofAquatic Resources Journal, 3(1), 17-26.

Rumahlatu, D. (2012). Respons perilaku bulu babi Deademasetosum terhadap logam berat kadmium. Bumi Lestari Journal of Environment, 12(1), 45-54.

Rumahlatu, D. (2012). Aktivitas Makan dan Pertumbuhan Bulu Babi Deademasetosum Akibat Paparan Logam Berat Kadmium (FeedingActivityandGrowth Sea UrchinsDeademasetosum Due toHeavy Metal CadmiumExposure). ILMU KELAUTAN: Indonesian Journalof Marine Sciences, 17(4), 183-189. 
Satyawan, N. M., Wardiatno, Y., \& Kurnia, R. (2014). Keanekaragaman spesies dan zonasi habitat echinodermata di perairan pantai semerang, lombok timur (DiversityofSpeciesand Habitat ZonationofEchinoderm in SemerangCoastalWaters, East Lombok). J. Biol. Tropis, 14, 83-92.

Sese, M. R., Annawaty, A., \& Yusron, E. (2018). Keanekaragaman Echinodermata (Echinoidea Dan Holothuroidea) Di Pulau Bakalan, Banggai Kepulauan, Sulawesi Tengah, Indonesia.Scripta biologica, 5(2),73-77

Setiawan, Y. J., \& Siregar, S. H. (2012). Analisis Kepadatan Bulu Babi Diadema Setosum Pada Kondisi Terumbu Karang Berbeda Di Desa Mapur Kepulauan Riau. Jurnal IImu Lingkungan, $5(01)$.

Syam, A. R., \&Andamari, R. (2017). Populasi dan tingkat pemanfaatan bulu babi (Echinoidea) di Padang Lamun Pulau Osi, Seram Barat, Maluku Tengah. Jurnal Penelitian Perikanan Indonesia, 8(4), 31-37.

Supono, S., \& Arbi, U. Y. (2012). Abun dance and Diversity of Echinoderm in Pari Island, Seribu Islands. Jurnal IImu dan Teknologi Kelautan Tropis, 4(1)

Toha, A. H. A. (2019). Keragaman genetik bulu babi (Echinoidea). Biota: Jurnal IImiah IImu-IImu Hayati, 12(2), 131-135.

Vindia, W. I., Julyantoro, P. G. S., \& Wulandari, E. (2019). Asosiasi Echinodermata pada Ekosistem Padang Lamun di Pantai Samuh, Nusa Dua, Bali. Journal of Marine and Aquatic Sciences, 5(1), 100-108.

Yunita, R. R., Suryanti, S., \& Latifah, N. (2020). BiodiversitasEchinodermata pada Ekosistem Lamun di Perairan Pulau Karimunjawa, Jepara. Jurnal Kelautan Tropis, 23(1), 47-56.

Yudasmara, G. A. (2013). Keanekaragaman Dan Dominansi Komunitas Bulu Babi (Echinoidea) Di Perairan Pulau Menjangan Kawasan Taman Nasional Bali Barat. JST (Jurnal Sains dan Teknologi), 2(2).

Yusron, E. (2010). Keanekaragaman Jenis Ekhinodermata Di Perairan Likupang, Minahasa Utara, Sulawes Utara. ILMU KELAUTAN: Indonesian Journalof Marine Sciences, 15(2), 85-90. 